American Journal of Biochemistry and Biotechnology 2 (4): 170-174, 2006

ISSN 1553-3468

(C) 2006 Science Publications

\title{
Surface Properties of Cell-treated Polyethylene Terephthalate
}

\author{
${ }^{1}$ Bing Shi, ${ }^{2}$ Hong Liang, ${ }^{1}$ Thomas B. Kuhn and ${ }^{1}$ Lawrence K. Duffy \\ ${ }^{1}$ Department of Chemistry and Biochemistry, University of Alaska Fairbanks, AK 99775, USA \\ ${ }^{2}$ Department of Mechanical Engineering, Texas A\&M University, TX 77840, USA
}

\begin{abstract}
The materials used in artificial joints undergo degradation through fatigue and corrosive wear in human body. The lifetime for well-designed artificial joints like hip joints is at most 12 years and a patient will usually have two total joint replacements during his/her lifetime. Tissue engineering, an alternative to total joint implantation, is the replacement of damaged tissue with the tissue that is designed and constructed to meet the needs of the individual patient. In this study, polyethylene terephthalate (PET) in the form of overhead transparency films were investigated on their cell interactions and the tribological properties as an alternative tissue-engineering matrix. The base material of the transparency films is PET. Cell culture methods as well as atomic force microscope (AFM), contact angle goniometer, confocal microscope and universal tribotester were used to study the properties of the substrate materials and the interactions between the surface and the substrate materials. Results showed that cells grew on the substrate of the base materials of the PET. The tribological properties of the slides have been changed after being cell-treated.
\end{abstract}

Key words: Polyethylene terephthalate (PET), 3T3 cells, atomic force microscope (AFM)

\section{INTRODUCTION}

The materials used in artificial joints, such as stainless steel, titanium alloy, polymers and ceramic composites, undergo degradation through fatigue and corrosive wear from load-bearing and the aqueous ionic environment of the human body. At the same time, deposits of inorganic salts can scratch weight-bearing surfaces, making artificial joints stiff and awkward. The increasing life expectancy of an aging population and the need to surgically treat arthritis in increasing numbers of young patients, are placing greater demands on the durability of artificial joints. At present the lifetime for well-designed artificial joints like hip joints is at most 12 years. A patient can only have two total joint replacement surgeries during his/her lifetime, each replacement resulting in the lose of some of their own remaining sound bone.

Tissue engineering is a new alternative to total joint implantation. Tissue engineering is the replacement of living tissue with one that is designed and constructed to meet the needs of the individual patient ${ }^{[1]}$. This interdisciplinary science integrates the fields of biomaterials, cell biology, biochemistry and clinical medicine. The goal of tribology is to create biomaterials that functionally repair damaged or diseased tissues and organs ${ }^{[2]}$.

Joint cartilage normally does not regenerate in the body; hence, damage from injury or illness tends to increase over time. Current clinical practices treat damaged cartilage by the use of tissue transplants or prosthetic implants. While these surgical procedures restore joint function, they can also present long-term complications. Tissue engineering focuses on the regeneration of tissues using biocompatible materials as an alternative to cartilage replacements. Over the last decade the research has focused on cell-based repair approaches for articular cartilage lesions. Utilizing engineering principals, tissues can be generated using scaffolds that support encapsulated cells and their production of tissue matrix materials ${ }^{[3-8]}$.

Polyester is the base material of overhead transparency films. Both sides of the base film are coated with toner receptive coatings, an inkjet receptive coating on one side and an antistatic coating to optimize stream feeding on the other side. The base sheet is made of biaxially oriented polyethylene terephthalate (PET). PET is a linear, aromatic polyester, made from benzene-1,4-dicarboxylic acid and ethane-1,2-diol. The chemical structure of PET is<smiles>CC(C)(C)OCCOC(=O)c1ccc(C(C)(C)C)cc1</smiles>

PET is extensively used for soft-drink bottles and can be relatively easily chemically recycled. It is clear, tough, safe, light, transparent, reliable, chemicalresistant, easily moldable and economical. Because of their stability, PET is being treated as a biomaterial, especially in implantation. Current medical applications of PET include implantable sutures, surgical mesh, vascular grafts, sewing cuffs for heart valves and components for percutaneous access devices ${ }^{[9-13]}$.

In this study, the commercial PET films were investigated for their surface properties including

Corresponding Author: Lawrence K. Duffy, Department of Chemistry and Biochemistry, University of Alaska Fairbanks, AK 99775, USA 
microstructure and the wettability of the substrate materials, interactions of the substrates with cells and the tribological properties. Atomic force microscope (AFM), confocal microscope and universal tribotester were used to observe cell growth on the PET substrate of the films. As the cells grow, the tribological properties of the PET slides have been changed.

\section{MATERIALS AND METHODS}

Two kinds of PET films were used in this research: $0.14 \mathrm{~mm}$ thick transparency-1 (TR-1) and $0.10 \mathrm{~mm}$ thick transparency-2 (TR-2). TR-1 is thicker and rougher. TR-2 is thinner and smoother. Atomic Force Microscope (AFM) was used to observe and measure the morphology of the film surfaces, as seen in Fig. 1 and 2. The surface of the TR-1 has separate asperities, which are randomly arranged. In TR-2 the surface asperities are well organized and densely packed, which make the TR-2 surface flat and smooth.

The cells used in these experiments were 3T3 fibroblast from ATCC. TR-1 and TR-2 samples were sterilized in $70 \%$ ethanol for $5 \mathrm{~min}$ and then exposed under UV light for 20 min on both sides in the laminarflow hood (NUAIR) to provide aseptic conditions for cell culture. During this treatment process, some of the TR-1 and TR-2 coatings were disturbed. The culture media for 3T3 fibroblasts was Dulbecco's Modified Eagle Medium (DMEM, GIBCO), Fetal Bovine Serum (FBS) and penicillin-streptomycin (GIBCO) solution. 3T3 fibroblast cells were cultured on the transparency film samples in a plastic cell culture dish. The cell densities for cell culture used for plating were 100,000 cell $\mathrm{mL}^{-1}$ and 200,000 cell $\mathrm{mL}^{-1}$. The cells were grown for $48 \mathrm{hrs}$ after plating and then observed using an inverted phase-fluorescence microscope.

The wettability of the transparency films was investigated using contact angle goniometer. Friction tests were conducted using the pin-on-disk mode of a Universal Micro-Tribotester (UMT, CETR). Reciprocating friction tests were performed using a rectangular aluminum holder which was fabricated in order to conduct the lubricated friction tests. The aluminum pin was $6.35 \mathrm{~mm}$ in diameter and the test materials were held inside the holder by two aluminum bars that are attached to the bottom of the holder. The normal load was $5 \mathrm{mN}$ and the velocity of the slider was $10 \mathrm{~mm} \mathrm{sec}^{-1}$. The tests lasted $10 \mathrm{~min}$ and each individual test performed three times. The lubricant used was 1\% Bovine Serum Albumin (BSA) solution in $0.15 \mathrm{M} \mathrm{NaCl}$. Friction tests for 3T3 fibroblast treated transparency film samples were performed after the cells were cultured on the transparency film for $48 \mathrm{hrs}$.

\section{RESULTS AND DISCUSSION}

Wettability of PET films: Wettablity is a surface property of a material. The surface tension value can be
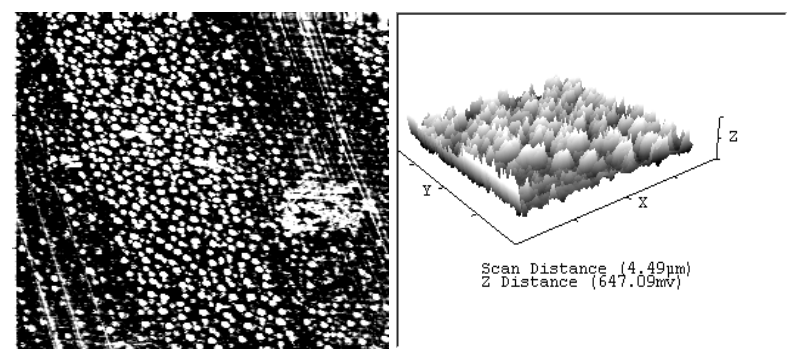

Fig. 1: AFM image of TR-1 Left, 2-Dimage; Right, 3D image
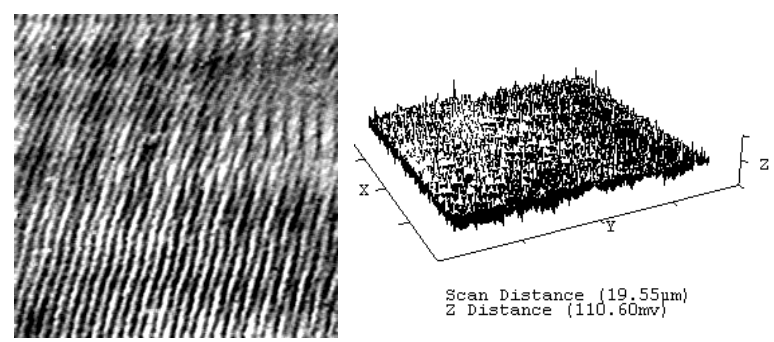

Fig. 2: AFM images of TR-2 Left, 2-D image; Right, 3-D image
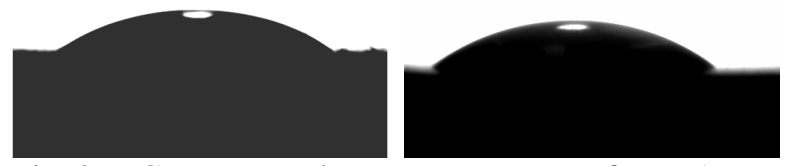

Fig. 3: Contact angle measurements of TR-1, and TR2 samples Left: TR-1; Right: TR-2
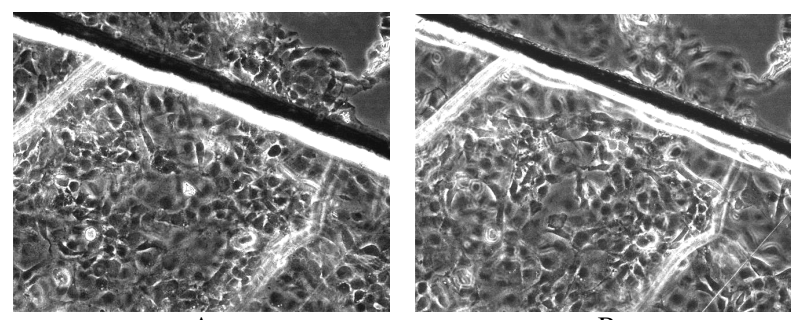

A

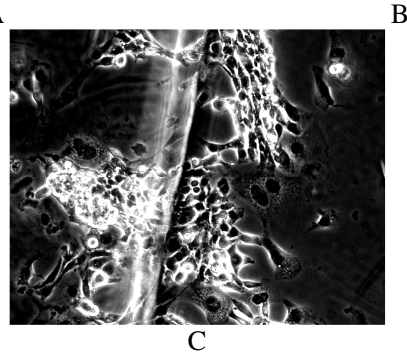

Fig. 4: Cell culture on TR-1, phase contrast microscope (20x), A edge area-focused on the bottom; B: same edge area- focused on the top, $\mathrm{C}$ : edge area - focused on the edge

utilized to determine the wettability by measuring the contact angle between a solid surface and a droplet of liquid on the surface. The measurements were conducted using a goniometer. Matrix materials have an attractive (hydrophilic) or repulsive response (hydrophobic) to the water. The wettability of a material is determined by the surface polarity of the 


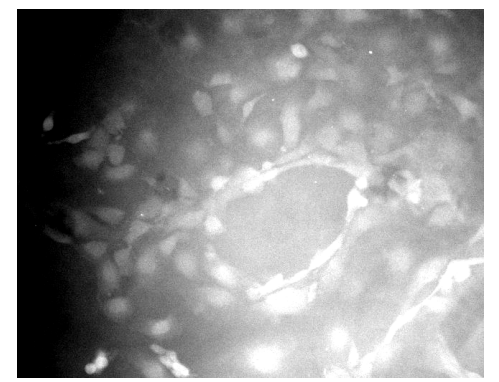

Fig. 5: Cell culture on TR-1, fluorescence microscope (20x)

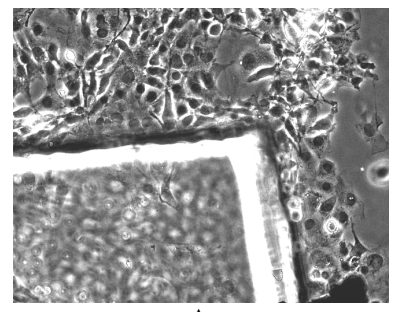

A

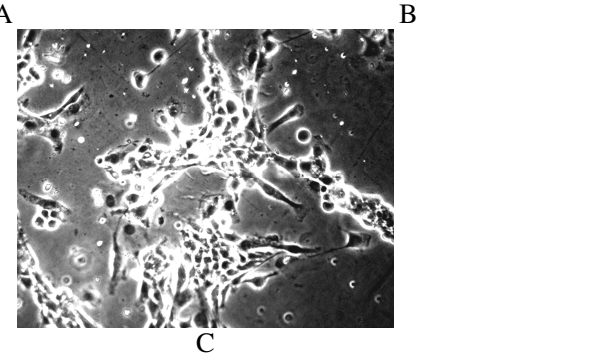

Fig. 6: Cell culture on TR-2, phase contrast microscope (20x), A: corner area-focused on the bottom; B: same corner area -focused on the top; C: center area of the sample
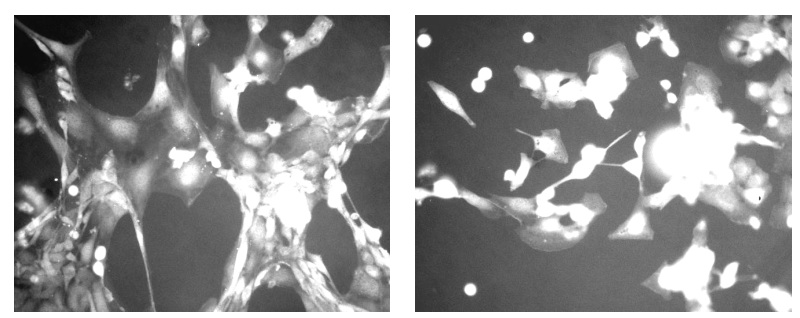

Fig. 7: Cell culture on TR-2, fluorescence microscope (20x)

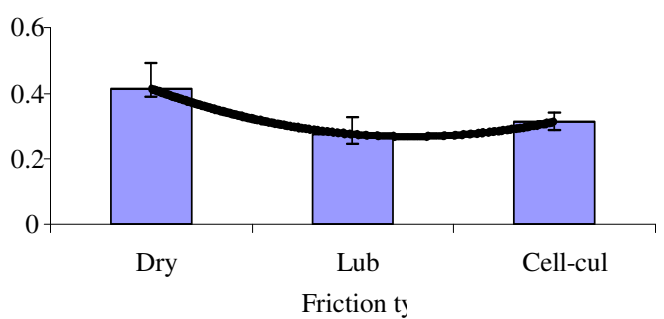

Fig. 8: Comparison of coefficients of friction of different type of tests of TR-1

materials. The measurement showed that the contact angles of TR-1 and TR-2 are 55.7 (StDev 0.69) and $53.7^{\circ}$ (StDev 0.07 ). Since PET, the polymer component

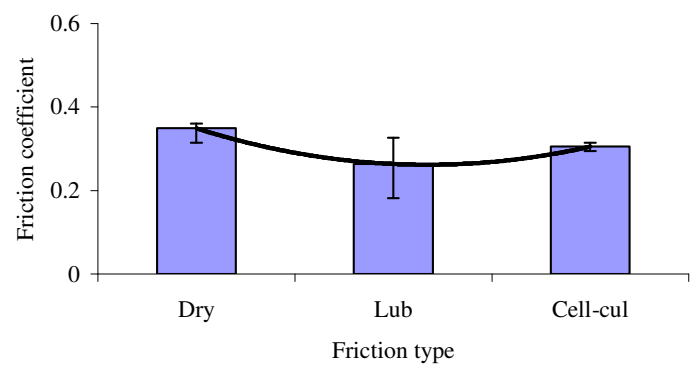

Fig. 9: Comparison of coefficients of friction of different type of tests of TR-2

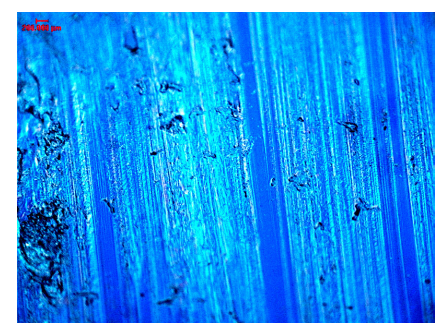

Fig. 10: Microscope image of TR-1 after the friction test Left: dry friction test; 20x; right: lubricated friction test, 20x

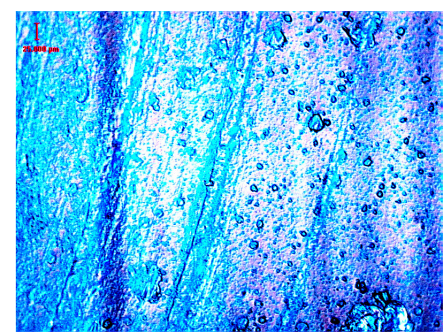

Fig. 11: Microscope image of TR-2 after the friction test Left: dry friction test, 10x; right: lubricated friction test, 20x

of TR-1 and TR-2 samples, can accept hydrogen bonds from water, TR-1 and TR-2 are partially wettable which is cocurtant with the water spreading out and the contact angles being less than $90^{\circ}$ (Fig. 3). After the samples were cell-treated, they became totally wettable. The water drops spread out immediately and the contact angle is about 0 .

Visualizing cells: Cells adhere to each other and to the materials through the points of contact with cell adhesive proteins. The cells secret extracellular matrix (ECM) materials, which are various biopolymers and small molecules. The ECM is composed of mainly collagen proteins, which are connected to each other by four kinds of bonding: ionic bond; hydrogen bond; van de Waals attraction; and hydrophobic force. Biomaterials like PET provide the matrix sites that the proteins can combine with and allow for the cells growth. Cellular adhesion is a complex process involving cell and material interactions. The process has four stages: protein adsorption on the surface, contact of the rounded cells, attachment of cells to the substrates and finally spreading of cells. 
After $48 \mathrm{hrs}$ in culture, cells were attached to the substrates at both concentrations $\left(100,000\right.$ cell $\mathrm{mL}^{-1}$ and 200,000 cell $\mathrm{mL}^{-1}$ ) and grew on the PET. The 3T3 cells grew on both the surface of the coatings and the exposed PET. Since both TR-1 and TR-2 are transparent, they were observed under the phase contrast microscope (Fig. 4 and 6). A fluorescence microscope was also used (Fig. 5 and 7) but the coated TR-1 and TR-2 film had a relatively high background fluorescence. The areas where the coatings were totally peeled off had little background fluorescence.

3T3 cells were observed growing on both sides of TR-1. Cells grew less in the middle of TR-1 than in the edge area. Cells attached to the edges were well spread and formed monolayers. The cells attached to the middle area were well spread while in other areas, cells were either isolated single cells or formed clumps. Areas without coatings showed more attached cells than areas with coatings. Cells attached to the monolayercoated areas, but not to those areas where the peeled coatings folded over.

TR-2 showed more cells attached to the edge area than in the middle of TR-2, but the cell number was higher than for TR-1. The cells in the middle of the TR2 were well spread and formed monolayers. Cells also grew on both sides of the TR-2, but they did not grow on the areas where peeled coatings were folded over. TR-2 coatings had lower background fluorescence than TR-1.

Friction tests: Friction tests of TR-1 and TR-2 showed an improvement in friction coefficients of lubricated and cell culture tests versus the dry film (Fig. 8 and 9).

TR-1 and TR-2 had higher dry friction coefficients (0.41 and 0.35$)$ than that of lubricated friction coefficients $(0.28$ and 0.26$)$ and cell culture friction coefficients $(0.31$ and 0.31$)$. The lubricant (BSA) decreased the friction coefficients after the lubricant molecules bonded to the surface of TR-1 and TR-2, acting as an anti-friction agent. TR-1 and TR-2 were treated with ethanol, which damaged the surface coatings, the TR- 1 and TR- 2 surfaces of the cell culture samples were not uniform because of the peeling of and folding over of the coatings. The cell-treated friction tests showed higher average friction coefficients compared to the lubricated friction tests. TR-1 has a rougher surface profile and showed higher friction coefficients compared to TR-2.

There were running-in periods for both of the dry friction tests due to roughness effects of coatings on the surfaces of TR-1 and TR-2. After modification of the surface by the lubricant there were still running-in periods during the lubricated friction tests but with less variation (data not shown). Since the cell growth experiment had modified the surface before the friction tests, no obvious running-in periods were observed during the tests. From the images after the friction tests, grooves and scratches, debris of the coatings and the transfer of materials were observed in the cell culture friction tests (Fig. 10 and 11).

In this study both of the concentrations $(100,000$ cell and 200,000 cell $\mathrm{mL}^{-1}$ ) worked for cell culture. The PET film areas with the non-polar coating had low confluency of cells while the areas where the coating had peeled off had much higher cell confluency which showed that PET is a good substrate for cell growth. TR-1 and TR-2 are not porous matrix materials, but cells secreted ECM within a short time and could attach to the surface of the samples. BSA and cell-treated films showed lower friction coefficients. PET has the properties to provide low friction surface and allow for recolonization of cells under in vivo conditions. There will be less wear on in vivo lubrication which will increase the longevity of artificial biomaterials.

\section{ACKNOWLEDGEMENTS}

This research was funded in part by the Department of Chemistry and Biochemistry of University of Alaska Fairbanks and NIH U54NS41069 grant and was partially sponsored by the NSF grant number CMS-0239136. The authors would like to acknowledge Dr. Dianne Rekow for the helpful discussions and suggestions during the study.

\section{REFERENCES}

1. Vacanti, J.P. and R. Langer, 1999. Tissue engineering: The design and fabrication of living replacement devices for surgical reconstruction and transplantation, Lancet, 354: 132-134.

2. Liang, H., B. Shi, A. Fairchild and A. Cale, 2004. Applications of plasma coatings in artificial joints: An overview. Vacuum, 73: 317-326.

3. Service, R.F., 1995. Out of the Lab, Into the Body, Science, 270, 231.Caplan A.I., Elyaderani M., Mochizuki Y., Wakitani S., Goldberg V.M. 1997. Principles of Cartilage Repair and Regeneration, Clin. Orthop., 342: 254-269.

4. Grande, D.A., A.S. Breitbart, J. Mason, C. Paulino, J. Laser and R.E. Schwartz, 1999. Cartilage tissue engineering: Current limitations and solutions. Clin. Orthop., 367: S176-185.

5. Temenoff, J.S. and A.G. Mikos, 2000. Review: Tissue engineering for regeneration of articular cartilage. Biomaterials, 21: 431-440.

6. Raimondi, M.T., F. Boschetti, L. Falcone, G.B. Fiore, A. Remuzzi, E. Marinoni, M. Marazzi and R. Pietrabissa, 2002. Mechanobiology of engineered cartilage cultured under a quantified fluid-dynamic environment. Biomechan. Model Mechanobiol., 1: 69-82.

7. Ashammakhi, N. and P. Ferretti, 2003. Topics in tissue engineering, 1, e-book: www.tissueengineering-oc.com. 
8. Metzger, A., Restore Medical Inc. 2004. Polyethylene Terephthalate and the Pillar ${ }^{\text {TM }}$ Palatal Implant: its historical usage and durability in medical applications, dentalimplants-usa.com.

9. Illingworth, B., K. Tweden, R. Schroeder and J.D. Cameron, 1998. In vivo efficacy of silver-coated (silzone) infection-resistant polyester fabric against a biofilm-producing bacteria, Staphylococcus Epidermidis. J. Heart Valve Dis., 7: 524-530.

10. Homsy, C.A., K.E. McDonald, W.W. Akers, C. Short and B.S. Freeman, 1968. Surgical suturecanine tissue interaction for six common suture types, J. Biomed. Mater. Res., 2: 215-230.
11. Vinard, E., R. Eloy, J. Descotes, J. Brudon, H. Guidicelli, J. Magne, P. Patra, R. Berruet, A. Huc and J. Chauchard, 1988. Stability of performances of vascular prostheses retrospective study of 22 cases of human implanted prostheses. J. Biomed. Mater. Res., 22: 633-648.

12. Klinge, U., B. Klosterhalfen, J. Conze, W. Limberg, B. Obolenski, A. Öttinger and V. Schumpelick, 1998. Modified mesh for hernia repair that is adapted to the physiology of the abdominal wall. Eur. J. Surg., 164: 951-960.

13. von Recum, A.F., 1984. Applications and failure modes of percutaneous devices: A review. J. Biomed. Mater. Res., 18: 323-336. 